https://helda.helsinki.fi

\title{
Against the Vagueness Argument
}

\section{Tahko, Tuomas}

2009

Tahko, T 2009 , ' Against the Vagueness Argument ' , Philosophia : Philosophical quarterly of Israel , vol. 37 , no. 2 , pp. 335-340 . https://doi.org/10.1007/s11406-008-9172-2

http://hdl.handle.net/10138/27358

https://doi.org/10.1007/s11406-008-9172-2

publishedVersion

Downloaded from Helda, University of Helsinki institutional repository.

This is an electronic reprint of the original article.

This reprint may differ from the original in pagination and typographic detail.

Please cite the original version. 


\title{
Against the Vagueness Argument
}

\author{
Tuomas E. Tahko
}

Received: 31 August 2008 / Revised: 15 October 2008 / Accepted: 16 October 2008

(C) Springer Science + Business Media B.V. 2008

\begin{abstract}
In this paper I offer a counterexample to the so called vagueness argument against restricted composition. This will be done in the lines of a recent suggestion by Trenton Merricks, namely by challenging the claim that there cannot be a sharp cut-off point in a composition sequence. It will be suggested that causal powers which emerge when composition occurs can serve as an indicator of such sharp cutoff points. The main example will be the case of a heap. It seems that heaps might provide a very plausible counterexample to the vagueness argument if we accept the idea that four grains of sand is the least number required to compose a heap-the case has been supported by W. D. Hart. My purpose here is not to put forward a new theory of composition, I only wish to refute the vagueness argument and point out that we should be wary of arguments of its form.
\end{abstract}

Keywords Vagueness $\cdot$ Composition $\cdot$ Merricks $\cdot$ Heaps $\cdot$ Sorites $\cdot$ Causal powers

Unrestricted composition is a commonly accepted mereological principle, which states that for any set of entities, there is a further entity, namely their mereological sum. Those of us who think that, for instance, the sum of my nose and the Eiffel tower should not be a further entity wish to deny unrestricted mereological composition and opt for some sort of restricted composition. However, restricted composition of any kind faces a serious objection: the so called vagueness argument. The vagueness argument claims that restricted composition is irredeemably vague, i.e. there is vagueness over which mereological sums really exist. This has an unacceptable result, as it thus seems that existence is vague. While our thoughts and language can certainly be vague, the idea that existence could be vague is not appealing. Here I will challenge the vagueness argument against restricted composition.

The first version of the vagueness argument is often credited to David Lewis (1986), but it is Theodore Sider (2001) who has inspired the latest discussion. Lewis

T. E. Tahko $(\bowtie)$

Department of Philosophy, Durham University, 50 Old Elvet, Durham DH1 3HN, UK

e-mail: tuomas.tahko@durham.ac.uk 
and Sider are both proponents of the vagueness argument, while e.g. Trenton Merricks $(2001,2005,2007)$ and Daniel Nolan (2006) have questioned its validity (for different reasons). In this paper I will offer a counterexample to the vagueness argument by developing an idea put forward by Merricks, namely that there is a clear sense in which there can be a sharp cut-off point in a composition continuum. ${ }^{1}$ I will elaborate on his examples which rely on causality, and show that the basic idea is correct and serves as a counterexample to the vagueness argument, even though Merricks's own examples can certainly be questioned. On a more speculative note I wish to suggest that we should be wary of any arguments from vagueness that claim to have ontological implications.

The main focus will be the first premise of the vagueness argument, i.e. the claim that if composition is restricted, then it is sometimes vague whether certain particles compose a certain object or not. The case that Merricks (2007) offers against this premise is that of a sequence of straws loaded on a camel's back, resulting in the camel's back breaking at some point. ${ }^{2}$ According to Merricks, it is quite plausible that the breaking of the camel's back has a sharp cut-off point-a particular straw. Even if there is some room for doubt in the camel's case, he suggests, we can replace the camel with a trap door that falls wide open when a sufficient number of straws have been added on top of it (cf. Merricks 2007: 5n). These examples, however, can be questioned, as it would seem that 'breaking' and 'open' allow at least for some vagueness. Further, as Merricks (2007: 118) points out, it is not quite as plausible that there would be a similar sharp cut-off point in, say, the case of baldness and the removal of individual hairs. Merricks contends that there is a difference between the cases at hand and a plausible explanation for this seems to be the fact that in the first case, something occurs: the camel's back breaks (or the trap door falls open) (ibid.). He insists that the addition of just a single straw can, contrary to the removal of a single hair, bring forward a new causal power.

If this is right, we can put forward a more general point. In any sorites series, if the move from the previous state to the next state brings forward a change in the causal powers of the related entities, we have a sharp cut-off at hand. The addition of each individual straw (either on the camel's back or on the trap door) adds to the collective weight of the straws and presumably there is a sharp cut-off point to the weight that a camel's back can take, or so the argument goes. The addition of a single hair on a bald head does not seem to have any such implications. At some point we would cease to call the head 'bald', but this seems to be the only apparent change, thus we have a case of linguistic vagueness. It is important to appreciate the difference between these cases, for if there is vagueness over the first one, then it is hard to see how it could only be the relatively unproblematic, linguistic sort. That is, if the cut-off point for the causal powers induced by the collective weight of the straws - the breaking of the camel's back or the opening of the trap door-is not sharp, then the vagueness concerning this would appear to be in the world.

\footnotetext{
${ }^{1}$ As Merricks puts it, a 'composition continuum' is simply what Sider calls a 'continuous series of cases', a sequence (Merricks 2005: 623). I will use Merricks's terminology here, with apologies to any mathematicians who might be offended by the use of the notion of 'continuum' like this (thanks to an anonymous referee for pointing out this concern).

${ }^{2}$ In fact he introduced the example already in Merricks (2001: 127-28).
} 
I sympathise with the general line of Merricks's examples, but they might not be as plausible as he hopes. The problem is that you can easily introduce extra variables to these cases, namely, a small change even at the atomic level might affect the exact cut-off point in terms of the breaking of the camel's back or the trap door falling open. The point of the argument, supposedly, is that causal powers can be traced back to fundamental physical forces and that all causal powers are somehow supervenient on these fundamental forces. However, in Merricks's examples it is not completely straight-forward how this tracing should be done, thus there is room for vagueness. Let us grant him the idea for now though.

The question is whether there are any causal powers that emerge in the case of composition which would secure a sharp cut-off. Merricks argues that there are:

[A] composite object causes an effect $E$ non-redundantly only if $E$ is not caused by that object's parts working in concert. Thus a composite object's exercising non-redundant causal power-an object causing something non-redundantlycannot be reduced to what its parts cause working in concert. In this way, an object's exercising non-redundant causal power is irreducible to its parts (and their features and interrelations, etc.). I think that each and every composite object has non-redundant causal powers. So I think that composites have irreducible features. (Merricks 2005: 631-632.)

Merricks goes on to offer an example concerning a thinking person and the atoms that the person consists of, suggesting that it is the mental properties of persons that serve as non-redundant causal powers. He has his reasons for providing this particular example, but it seems that there are plenty of other, perhaps less controversial examples available. Consider a rock that falls to the ground, causing a depression (cf. Lowe 2005: $525 \mathrm{ff}$ ). The rock is composed of granite particles, but it would appear that the rock causing the depression in the ground cannot be reduced to these granite particles 'acting in concert', for the granite particles do not have any independent 'motive' to act together. That is, the granite particles are bound together and the only collective 'motive' that they might be said to have is that of composing the rock. Clearly, then, when the rock causes the depression in the ground, it is in virtue of the causal powers of the rock. The fact that the rock is composed of a particular set of granite particles is presumably an essential feature of the rock, but its causal powers cannot be reduced to its parts.

Interestingly, this line of thought, which is perfectly compatible with the passage quoted from Merricks above, also works as an argument against his nihilism about ordinary objects (cf. Merricks 2001). ${ }^{3}$ What is at issue now is whether the rock example is analogous to the straw example (or an idealised version of it), i.e. whether we can determine a sharp cut-off point in the composition continuum. So, if we remove one granite particle at a time from the rock, can we at any time observe a sharp cut-off in terms of its causal powers, namely, is there a change in the depression that it causes in the ground? On the face of it, it seems that there might be no such cut-off point, as the rock will certainly produce a depression of some sort each time after we have removed a granite particle, until there are no granite particles left (we can imagine that we have the

\footnotetext{
${ }^{3}$ In fact, Lowe (2005) uses the rock example exactly for this purpose.
} 
means to observe even the depression that a single particle would produce). However, although there is no substantial change in the causal powers of the rock in each case - no breaking of a back or a trap door falling open - there is certainly some sort of a change, albeit a rather minuscule one, each and every time we remove a granite particle. This change is of course the size of the depression that the rock causes in the ground (again, if we have the means to observe the effect of even a single particle, we would also be able to observe the difference between $n$ and $n-1$ particles). In effect, the causal powers of the rock change each time we remove even a single granite particle. Indeed, if we take causal powers to be essential features of entities, it seems that we have a different rock after each time we remove a particle.

Perhaps friends of unrestricted composition will not be convinced by these observations. After all, the sharp cut-off in a composition continuum required by Sider (2001: 123) calls for a case where a pair of adjacent cases in a continuous series are such that composition occurs in one, but not in the other. Clearly, our example above does not satisfy this criterion, as composition certainly occurs before and after we have removed a single granite particle from the rock. However, the question is: what is composed before and after the granite particle has been removed? A rock, certainly, but not the same rock. If the rock has different causal powers before and after we have removed one granite particle, as seems to be the case, then it is not the same rock after the operation. If you think that it is, then you must somehow account for a change in the causal powers of entities, and there does not seem to be much room to manoeuvre here. ${ }^{4}$ If Merricks is right, already this is enough to show that the argument from vagueness fails. However, let us see if we can construct an example which satisfies Sider's requirements more explicitly and does not leave any room for vagueness, contrary to Merricks's examples.

Consider a heap. We have the usual story about the grains of sand and the composition continuum that we get when grains of sand are added one by one-there seems to be no sharp cut-off point as to when a heap is formed. Yet some have entertained the thought that there might be one, namely four grains of sand. ${ }^{5}$ The idea is that for a bunch of grains to constitute a heap, at least one grain has to be stably resting on other grains. The exact physics aside, four seems to be the smallest number of grains able to fulfil this requirement. It may perhaps be objected that given this definition of 'heap', the composition continuum does not even arise. However, the definition of 'heap' hardly enters the picture. Given the story about causal powers that was introduced above, we can make the same point just by observing whether any new causal powers emerge with the addition of the fourth grain of sand. We know that

\footnotetext{
${ }^{4}$ One could perhaps suggest that we can account for the change in the causal powers of the rock simply in terms of the weight of the removed granite particle(s) (thanks to an anonymous referee for this objection). However, if one wishes to maintain that we are dealing with the same rock all the time and that we can add and subtract as many granite particles as we like, as this objection seems to imply, then it appears that a single granite particle and a mountain could be said to be the same rock, and this is surely implausible. If we instead adopt the view that causal powers are essential features of entities, we have a different rock in each case. Thus, the problem is that we do not have any plausible criteria for distinguishing between a single granite particle and a mountain if we insist that we are dealing with the same rock after removing one granite particle from the original.

${ }^{5}$ Cf. Williamson (1994: 213); the idea was originally put forward by Hart (1991/1992), see also Hart (2007).
} 
three grains of sand cannot form a stable heap, so if there are three grains on the ground so far, then all of them are necessarily in contact with whatever surface they rest on. What happens with the addition of the fourth grain is that, potentially, one of the grains could be above the ground level, not touching the surface. It is not essential that we call this formation of four grains of sand a 'heap', but what is essential is that this formation has features that cannot be present in any formation of only three grains of sand. For instance, the grain on top of the heap has a higher potential energy. So, no matter what the definition of the word 'heap' is, there is a clear sense in which any formation of three grains of sand has a narrower list of features than four grains arranged so that they form a pyramid-shaped structure. ${ }^{6}$

If more evidence is required, imagine that we drop a further, fifth grain of sand on top of the pyramid-shaped structure. What will happen? Well, this particular geometrical shape (which, I should add, is the only geometrical shape that a heap of four grains can take) has a feature that any arrangement of three grains of sand would certainly lack: it has a pointy tip and slopes on every side, thus the fifth grain of sand will slide down. The heap, then, has the ability to reflect any further grains of sand (or other such things) that could be dropped on it. If you observe an hourglass you can witness this causal power in action. In an hourglass the heap of sand which you get at the bottom is always pyramid-shaped and the pyramid grows gradually as the reflected grains of sand fill the space at the bottom of the hourglass - that is, the heap grows from the bottom towards the top and this is exactly due to the effect that the shape of the heap has towards any further grains that are dropped on top of it.

Here we have two adjacent cases in a continuous series which are such that in the first one composition does not occur, whereas in the second one it does. Three grains of sand do not compose an object in any relevant sense (as they cannot be heaped), but four grains of sand (which can be heaped) do. The grains of sand have a distinct feature: they can be arranged in a manner that saves space. As Hart (2007: 1) puts it, we make heaps for two reasons: the first is to save ground and the second to make it easier to scoop up the constituents of the heap when needed. We saw above that due to the particular shape that the heap naturally takes, it also has a number of other distinct features. What is interesting in this picture is that even as simple an object as a heap has distinct features too numerous to list. Clearly, more complicated objects will have an enormous amount of such features. The problem is that these features may appear gradually. For instance, smaller and larger heaps have different features, yet they are both objects of the same kind. Consequently, some features are essential to the object, but some are not. This is why it might be hard to tell when, exactly, does the sharp cutoff in a composition continuum occur; i.e. when do the essential features emerge, indeed, what are the essential features? In the case of heaps, as we have seen, this is relatively straight-forward, but more complicated objects will certainly cause problems, which is why Merricks's examples were not quite sufficient.

Consider conscious beings: Merricks (2005: 632) takes it that all the atoms in your body, a thinking person, save one in your left arm, fail to compose anything with mental properties because otherwise we would have two thinkers, you and that particular atom, where there clearly is only one. He then suggests that if you lose

\footnotetext{
${ }^{6}$ Perhaps I should note here that instead of grains of sand, we could use, say, lead atoms and construct the heap in a vacuum - this should help to remove any potential complications.
} 
that particular atom in your left arm, then the atoms that previously failed to compose a thinker suddenly go from composing nothing to composing you. This is misleading. Surely that particular atom in your left arm is not an essential part of you, exactly because you can lose that atom and still be you. According to Merricks, this example shows that mental properties give you non-redundant and irreducible causal powers, but we have a problem here: when do these mental properties emerge in a composition continuum? If we keep removing the atoms that compose you, then plausibly, at some point, your mental properties go as well.

Problems like the one described above may suggest that we should be sceptical about the existence of sharp cut-off points, as it indeed seems very hard to point one out in this case. However, the reason why this might seem impossible is not because there could not be a sharp cut-off point, but rather that we do not quite know what mental properties are. To be able to solve the problems that this particular composition continuum produces, we would need a completed philosophy of mind. This suggests that the nature of the objects that we are talking about is the crucial issue here. If we do not know what the essential features of an object are, then it is not a surprise that we cannot tell where the sharp cut-off point in a composition continuum occurs in the case of that particular object.

The upshot of this discussion is that there may be numerous cases where causal powers could help us to determine a sharp cut-off point in a composition continuum where one was not believed to exist. Note that just one plausible case is enough to refute the vagueness argument and I hope to have established at least that. Admittedly, if one wishes to construct a positive theory from this, quite a lot of work is required, and it might be that in some cases one would have to deny that composition occurs at all, because no clearly defined causal powers seem to emerge. My purpose here, however, is only to voice a concern about the vagueness argument and other arguments that take the form of the vagueness argument, as they seem to neglect a crucial part of the story. What we should examine are the essential properties of whatever entities we are dealing with as only by having a clear understanding of what, say, a conscious being is, can we hope to determine when and how a conscious being is composed.

\section{References}

Hart, W. D. (1991/1992). Hat-tricks and heaps. Philosophical Studies (Dublin), 33, 1-24.

Hart, W. D. (2007). Hyperheaps. International Journal of Philosophical Studies, 15, 121-123. doi:10.1080/09672550601143250.

Lewis, D. (1986). On the plurality of worlds. Oxford: Blackwell.

Lowe, E. J. (2005). How are ordinary objects possible? The Monist, 88, 510-533.

Merricks, T. (2001). Objects and persons. Oxford: Clarendon Press.

Merricks, T. (2005). Composition and vagueness. Mind, 114, 615-637. doi:10.1093/mind/fzi615.

Merricks, T. (2007). Remarks on vagueness and arbitrariness. Mind, 116, 115-119. doi:10.1093/mind/ fzm115.

Nolan, D. (2006). Vagueness, multiplicity and parts. Nous (Detroit, Mich.), 40(4), 716-737. doi:10.1111/ j.1468-0068.2006.00630.x.

Sider, T. (2001). Four-dimensionalism: An ontology of persistence and time. Oxford: Oxford University Press.

Williamson, T. (1994). Vagueness. London/New York: Routledge. 